\title{
Theoretical screening of novel electrode materials for lithium-ion batteries from industrial polymers
}

\author{
Huili Lu ${ }^{1} \cdot$ Jun $\mathrm{Yu}^{2} \cdot \mathrm{Ge}$ Chen ${ }^{1} \cdot$ Shaorui Sun ${ }^{1}$ \\ Received: 2 November 2018 /Revised: 1 April 2019 / Accepted: 9 April 2019 / Published online: 17 May 2019 \\ (C) The Author(s) 2019
}

\begin{abstract}
Organic polymers have the potential to be electrode materials for lithium-ion batteries due to their lower solubility, lower selfdischarge rates, high mechanical strength, greater flexibility, superior thermal stability, and versatility. In this paper, the density functional theory (DFT) was applied to investigate industrial polymers as electrode materials for lithium-ion batteries. The charge/discharge potentials of reported polymer electrode materials for lithium-ion batteries were collected, and the experimental values were fitted linearly with the values of $\Delta E_{\text {poly }}$ (as shown in Eq. (2b)) calculated with a single-molecule model to obtain a semi-empirical formula, which was subsequently applied to predict the charge/discharge potentials of industrial polymers. The results showed that 16th (polypyromellitic diphenyl sulfide), 17th (polypyromellitic diphenyl ether imine), and 23rd (polypyromellitic diphenylmethaneimine) materials have better electrochemical performance than the other materials in this paper, and we also find that the material, such as polypyromellitic diphenylmethaneimine, containing low electronegative heteroatom and electron-donating groups, has a low potential value.
\end{abstract}

Keywords Li-ion battery $\cdot$ Industrial polymer electrode materials $\cdot$ Single-molecule model

\section{Introduction}

Li-ion batteries have already played an important role in powering electronic equipment, grid energy storages, tools, and vehicles [1-3]. Electrode materials are one of the most important composite materials for improving the performance of lithiumion batteries [4]. Inorganic electrode materials, including $\mathrm{LiNiO}_{2}$ [5], $\mathrm{LiCoO}_{2}$ [6], $\mathrm{LiFePO}_{4}$ [7], and $\mathrm{LiMn}_{2} \mathrm{O}_{4}$ [8], have been researched in-depth and are extensively applied. However, inorganic materials have two disadvantages: one is limited mineral resources, particularly of $\mathrm{Co}$ and $\mathrm{Ni}$, the other is the production or recovery of inorganic compounds that require high temperatures and the release of large quantities of carbon dioxide, which is harmful to the environment [9].

Shaorui Sun

sunsr@bjut.edu.cn

1 Beijing Key Laboratory for Green Catalysis and Separation, College of Environmental and Energy Engineering, Beijing University of Technology, Beijing 100124, China

2 The Biological and Chemical College, Qinghai Nationalities University, Xining 030031, Qinghai, China
Recently, due to the unique properties, such as renewable sustainability, lower carbon dioxide emissions [10, 11], abundance of raw materials, and diverse types of structures, organic electrode materials have attracted considerable attention. To date, many organic electrode materials have been reported $[12,13]$, such as the conductive polymer $[14,15]$, organic radicals $[16,17]$, reduced carboxylate, and carbonyl compounds [18-26]. However, the disadvantages of organic compounds are that they can be easily dissolved and have low thermal tolerance, poor conductivity, and low mechanical stability $[27,28]$.

Organic polymers can reduce these problems because of their lower solubility, lower self-discharge rates, high mechanical strength, greater flexibility, superior thermal stability, and versatility $[19,29,30]$. These polymers include conducting polymers, radical polymers [31], polypyrrole [31], organosulfur derivatives $[32,33]$, and polymers with carbonyl groups [19, 34]. Recently, many new polymer electrode materials have been developed [25, 35-43]. In particular, Qichun Zhang et al. [44] discovered a high-performance all-plastic full battery (both the cathode and anode are poly (2,3dithiino-1,4-benzoquinone) (PDB)). The electrode is not easily dissolved in the electrolyte, meaning that the electrode has ultra-long cycle stability. These researchers' study 
demonstrated that the design and fabrication of highperformance all-plastic batteries is becoming possible.

Poly(ethylene terephthalate) (PET) material, which is highly difficult to degrade in a natural environment, has been reported as an anode material for lithium-ion batteries after a low-temperature solvothermal treatment [45], which shows that polymer waste is expected to become the electrode material of lithium-ion battery.

For many industrial polymers, their unit structures contain a carbon-oxygen double bond $(\mathrm{C}=\mathrm{O})$ in a conjugated carbon$\mathrm{yl}$ or carboxyl group, which is a typical characteristic for organic electrode materials of lithium-ion batteries. Thus, a theoretical screening study to find potential electrode materials from industrial polymers, which are produced on a large scale and at low cost, is required.

Previously, the single-molecule model accompanied with DFT calculation has been widely used to study small organic molecule as electrode materials for lithium-ion batteries, but it could not precisely predict the potential [46-50]. Recently, a high-throughput screening scheme based on the dispersioncorrected density functional theory (DFT-D) and organic crystal structure could accurately calculate the potential of organic electrode materials $[16,35,48,50-54]$.

For polymer materials, their crystal structures are easily deformed, and the crystallized phases always coexist with an amorphous phase, which means that it is difficult to accurately measure and describe the crystal structure of polymers. In the present study, the charge/discharge potentials of 11 reported polymer electrode materials for lithium-ion batteries was collected, and the experimental values were fitted linearly with the values of $\Delta E_{\text {poly }}$ (as shown in Eq. (2b)) calculated with a single-molecule model. After a mathematical treatment, a semi-empirical formula to predict charge/discharge potential of polymer electrode materials was set up, which was further applied to predicted more than 20 industrial polymers as electrode materials. Several materials with high potential and capacity are specified in the paper, and the calculation results

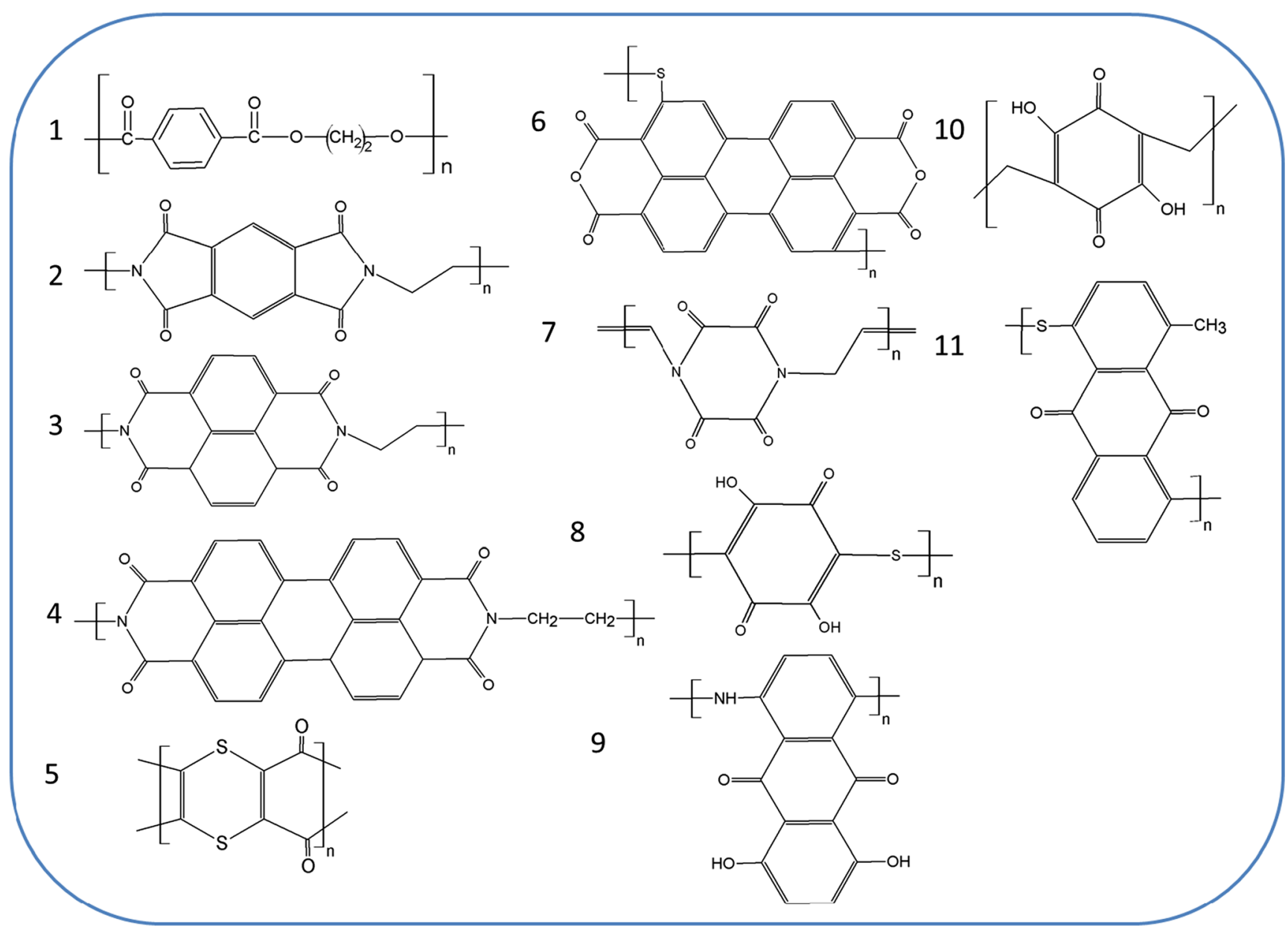

Fig. 1 Structures of the 11 types of reported industrial polymer materials. (1) Polyethylene terephthalate (PET); (2) polyimide-2; (3) polyimide-3; (4) urea-perylene diimide polymer; (5) poly(2,3-dithiino-1,4-benzoquinone); (6) 3,4,9,10-perylenetetracarboxylicacid-dianhydride(PTCDA) sulfide polymers; (7) N,N0-diallyl-2,3,5,6-tetraketopiperazine; (8) poly(2,5-dihydroxy-1,4-benzoquinonyl sulfide; (9) poly(5-amino-1,4dyhydroxy anthraquinone); (10) poly(2,5-dihydroxy-1,4-benzoquinone3,6-methylene); (11) poly(anthraquinonyl sulfide) 


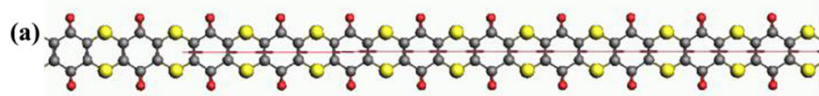

(b)

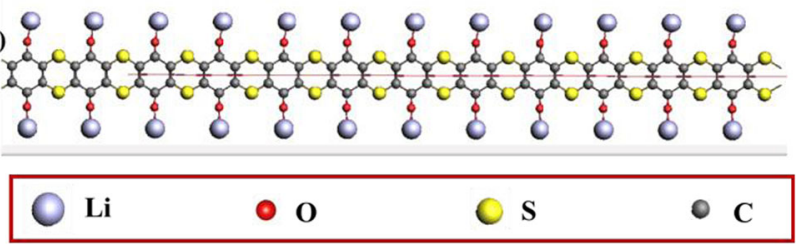

Fig. 2 a Structure of the delithiated PDB; $\mathbf{b}$ the structure of the lithiated PDB

demonstrate that the electronegativities of the substituents could adjust the charge/discharge potential of the polymer electrode materials for lithium-ion batteries.

\section{Computational method}

The Amsterdam Density Functional program package (ADF, version 2017) was applied in this study; geometries were optimized using the Perdew-Burke-Ernzerhof (PBE) exchange -correlation (xc) potential as implemented in the Amsterdam Density Functional-BAND (ADF2017) package [35, 36, 53, 55]. The double- $\zeta$ polarized (DZP) sets, the zeroth-order regular approximation (ZORA), normal numerical quality, and the large frozen core technology were applied in this work. A conductor-like screening model (COSMO) was used here to describe the acetonitrile solvent environment, and the dielectric constant was selected as 37.5 for the acetonitrile solvent. ADF-BAND uses chain periodicity, DZP basis is set with large frozen core, and the unit cell consists of repeating units. Constructing a one-dimensional chain periodic structure in
Fig. 3 a On the left is the energy band before the lithium is inserted, and on the right is the DOS; $\mathbf{b}$ on the left is the energy band after the lithium is inserted, and on the right is the DOS (a) $\operatorname{Energy~(eV)}$

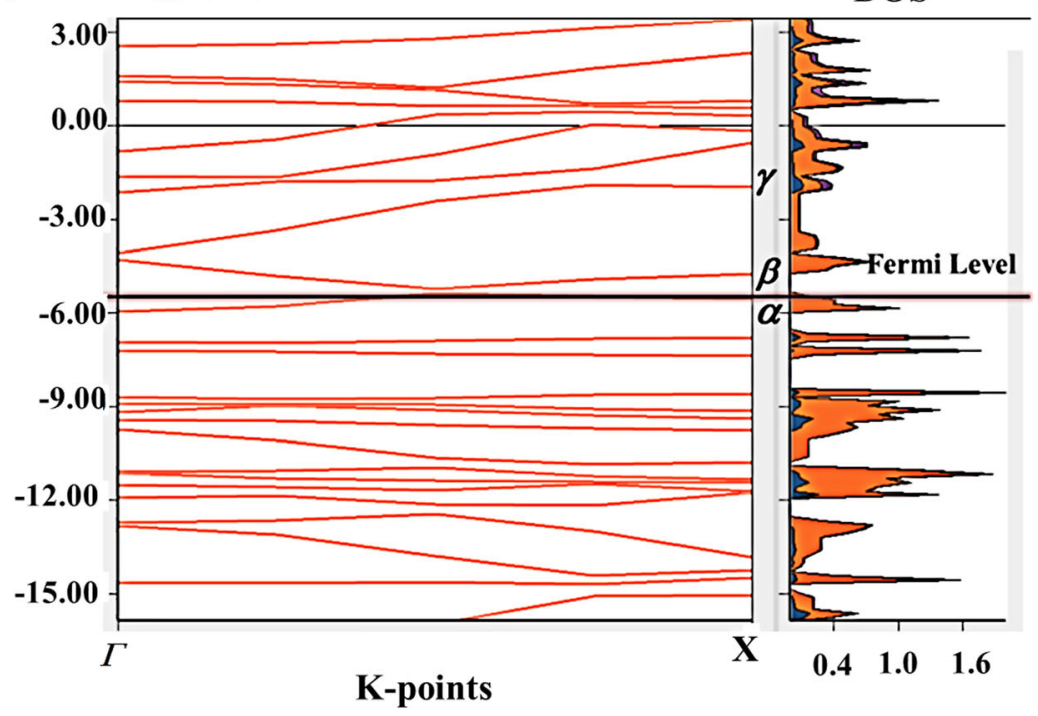

(b) Energy (eV)

DOS

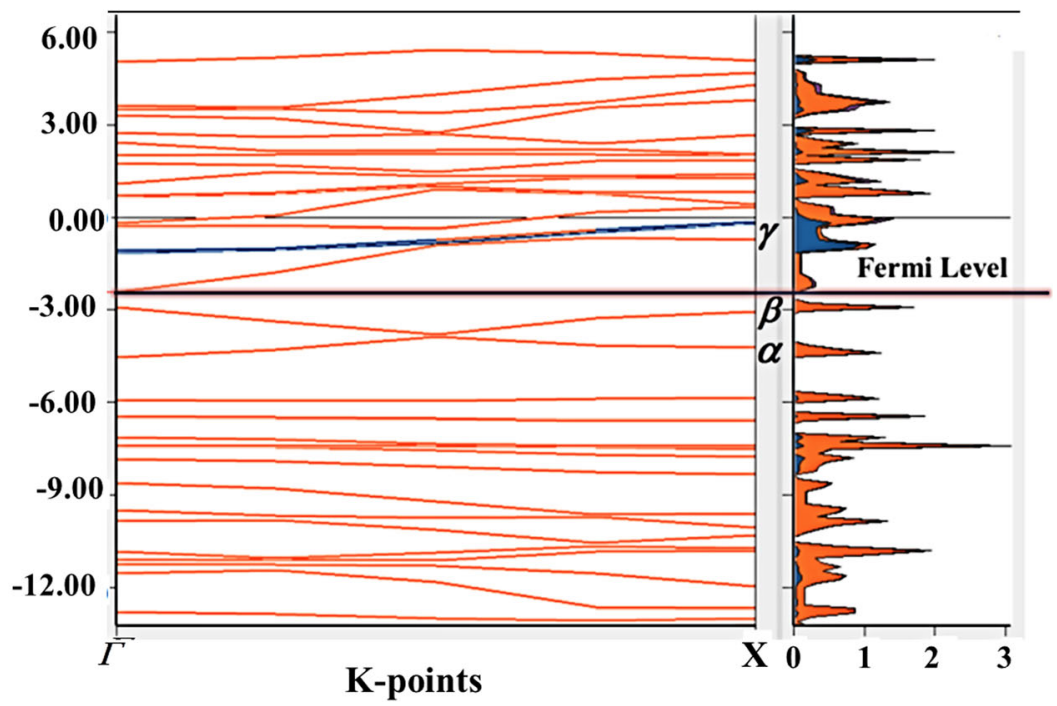


(a)

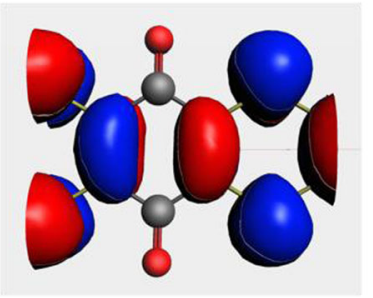

(b)

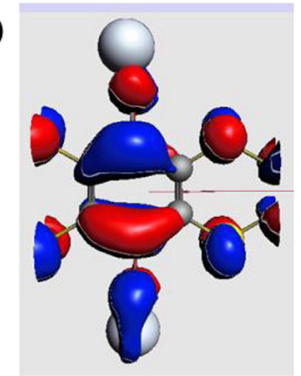

Fig. 4 a LUMO before lithium intercalation; b the HOMO after lithium intercalation

ADF-BAND based on a single molecular model. The chain periodic structures were optimized.

\section{Results and discussion}

As shown in Fig. 1, 11 reported polymer electrode materials were researched by theoretical methods [51], and one of the materials, poly(2,3-dithiino-1,4-benzoquinone) (PDB)) [44], is discussed in detail to present the calculation process.

The lithiated/delithiated structures of PDB (as shown in Fig. 2) are all fully optimized in acetonitrile with a relative permittivity of 37.5 through a single-molecule model, and the carbonyl group was considered the most suitable location for lithium. The lithiated/delithiated process can be simply explained as the double-bond breaking down into single bonds during the lithiation process and single bonds returning double bonds during delithiation [21-25]. In this way, the reaction occurred only near a single molecule, and each lithium only connected to an oxygen atom, as shown in Fig. 2 b.

The band structure of PDB is shown in Fig. 3. Figure 3 a shows the energy band structure and DOS (density of states) before lithium insertion, and Fig. $3 \mathrm{~b}$ shows the energy band structure and DOS after lithium insertion.

Table 1 Values of $\Delta E_{\text {poly }}$ and experimental potentials of the 11 types of industrial polymer materials

\begin{tabular}{lll}
\hline No. & $\begin{array}{l}\Delta E_{\text {poly }} \\
(\mathrm{V})\end{array}$ & $\begin{array}{l}\text { Experimental } \\
\text { potential }(\mathrm{V})\end{array}$ \\
\hline 1 & 0.82 & $0.90[45]$ \\
2 & 2.40 & $2.08[19,51]$ \\
3 & 2.83 & $2.15[19,51]$ \\
4 & 2.75 & $2.40[36,37]$ \\
5 & 3.31 & $2.75[44]$ \\
6 & 2.51 & $2.30[25,36]$ \\
7 & 2.85 & $2.40[36,38]$ \\
8 & 2.85 & $2.00[36,39]$ \\
9 & 2.21 & $2.00[36,40]$ \\
10 & 3.03 & $2.30[36,41]$ \\
11 & 2.28 & $2.20[36,42]$ \\
\hline
\end{tabular}

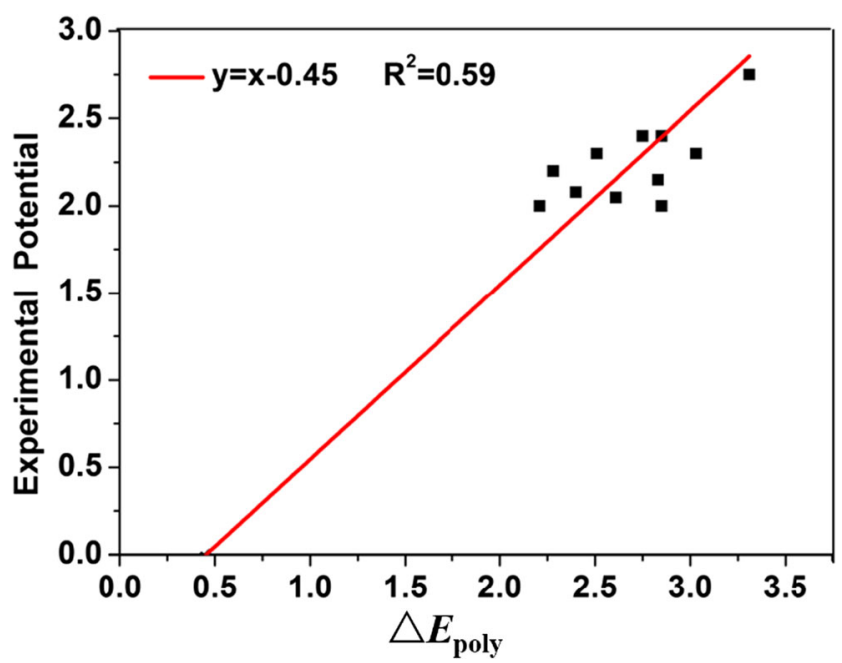

Figure 5 Linear relationship between experimental potential and $\Delta E_{\text {poly }}$

The band structure of PDB in the vicinity of the Fermi level is presented in Fig. 3; among the states, $\alpha, \beta$, and $\gamma$ are three different states near the Fermi level. For delithium, the $\alpha$ state was occupied, which was the valence band maximum (VBM); $\beta$ and $\gamma$ states are both unoccupied; and $\beta$ was the conductor band minimum (CBM). The band gap between $\alpha$ and $\beta$ was approximately $0.8 \mathrm{eV}$. After lithium was embedded, the electrons go into the $\beta$ band, and the Fermi level goes to the top of $\beta$ band. The occupied $\beta$ state becomes VBM, $\gamma$ becomes $\mathrm{CBM}$, and the band gap between $\beta$ and $\gamma$ decreases to $0.47 \mathrm{eV}$, which suggests that they are typical semiconductors. The band gaps were all small, but the energy bands $(\alpha, \beta$, and $\gamma)$ were flat, which implies they were all local states.

Before lithiation, the $\beta$ state was the LUMO (lowest unoccupied molecular orbit), and the charges were primarily distributed around carbon-carbon double bonds, as shown in Fig. 4 a. After lithiation, the electrons accompanied with lithium ions were transferred into the conjugated molecular orbit, and the $\beta$ state changes to the HOMO (highest occupied molecular orbit), in which charges are mainly distributed around the carbon atoms directly bonding to the carbonyl groups and carbonyl carbon atoms, as shown in Fig. 4 b.

Fig. 6 Structures of 26 types of industrial polymer materials. (1) Polybutylene terephthalate; (2) poly-p-phenylene terephthamide; (3) 3,3'-ODPA/ODA/PA; (4) polyethylene terephthalate; (5) polyethylene2,6-naphtalate; (6) poly( $p$-phenylene terephthalate); (7) polyterephthalic acid to naphthalenediol; (8) 3,4'-ODPA/ODA/PA (PAA); (9) PAI-1; (10) PAI-2; (11) fluorinated polyimide-1; (12) fluorinated polyimide-2; (13) fluorinated polyimide-3; (14) polyimide-1; (15) polyimide-2; (16) polypyromellitic diphenyl sulfide; (17) polypyromellitic diphenyl ether imine; (18) polybenzophenone tetracarboxylic acid $p$ dimethylcyclohexaneimine; (19) polybenzophenone tetracarboxylic acid dimethylcyclohexaneimine; (20) polyimide-3; (21) polybenzophenone tetraformyl triphenyl disulfide imine; ( 22 ) polybiphenyltetramethyleneimine; (23) polypyromellitic diphenylmethaneimine; (24) polydiphenyl ether tetraamine diamine; (25) polyethylene terephthalate; (26) polyetherketoneketone 
a

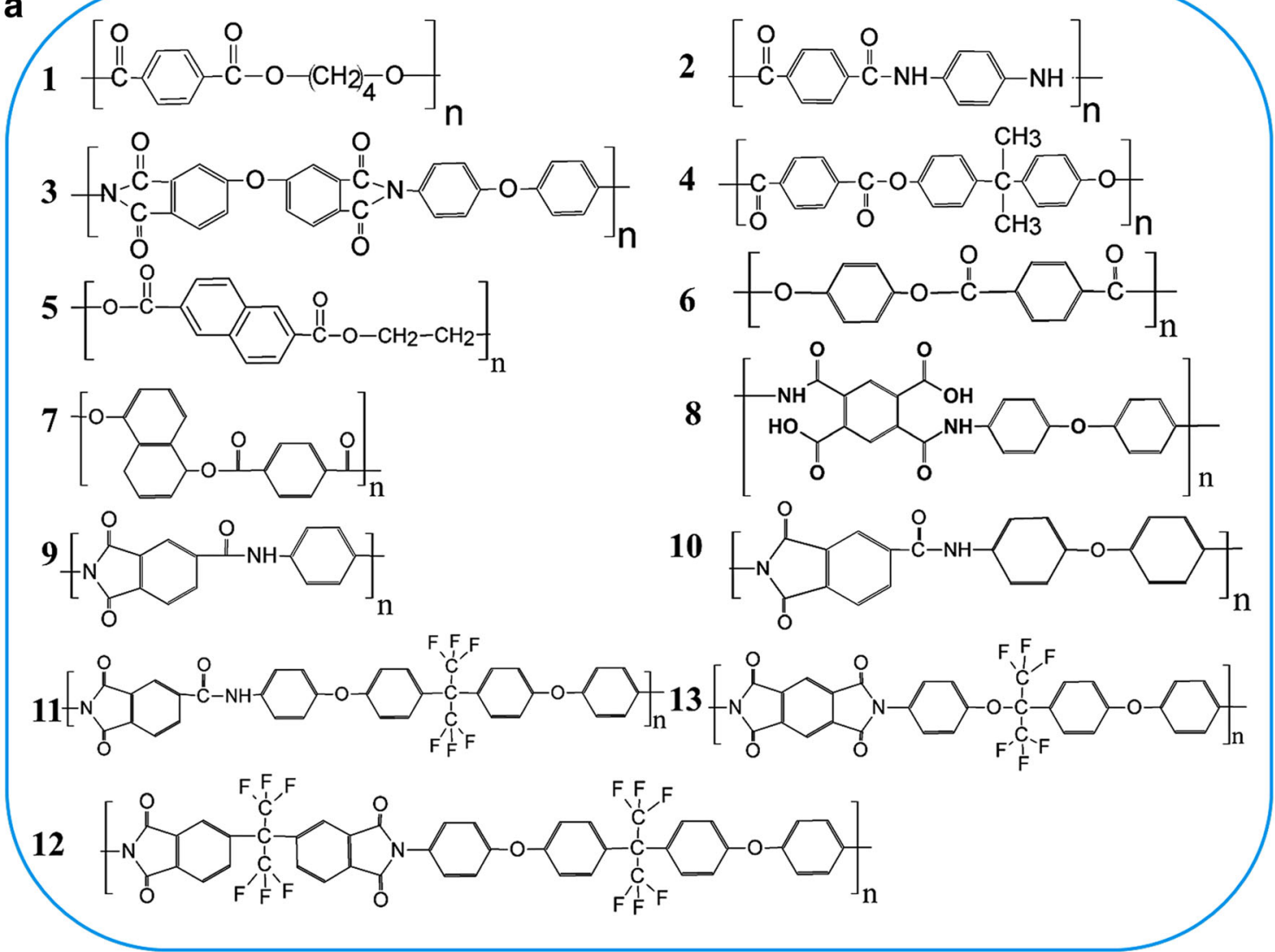

(n) 


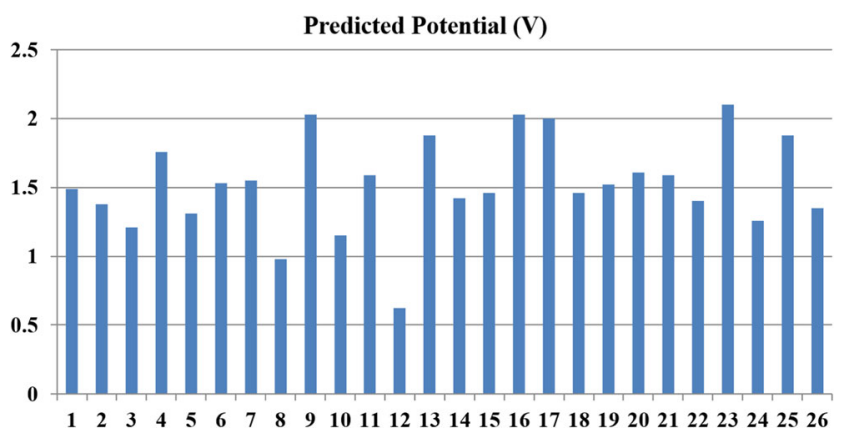

Fig. 7 Predicted potentials of 26 types of industrial polymer materials

When the crystal structure is known, the total energy of lithium crystal and materials can be determined; therefore, potentials can be calculated according to the following formula:

$V_{\text {cal }}=\frac{-\left(E_{\mathrm{A}-{ }_{\mathrm{n}} i}-E-\overline{\mathrm{A}} n E\right)}{n F}$

where $n$ is the number of transferred electrons, $F$ is the Faraday constant, $E_{\mathrm{A}}$ is the total energy for the electrode material with delithiation state, $E_{\mathrm{A}-\mathrm{Lin}}$ is that with lithiation state, $E_{\mathrm{Li}}$ is the total energy of lithium metal, and $V_{\text {cal }}$ is the calculated potential.

However, the crystal structures of many polymers are not known; therefore, we cannot determine the total energy of the polymer crystal. Therefore, a single-molecule model was used for the study and calculated using the Eq. (2a):

$V_{\text {pre }}=k \frac{-\left(E_{\mathrm{A}-\mathrm{Li}_{n}}-E_{\mathrm{A}}\right)}{n F}+c$

which could be further simplified as the following:

$V_{\text {pre }}=k \Delta E_{\text {poly }}+c$ and $\Delta E_{\text {poly }}=\frac{-\left(E_{\mathrm{A}-\mathrm{Li}_{n}}-E_{\mathrm{A}}\right)}{n F}$

$E_{\mathrm{A}}$ and $E_{\mathrm{A}-\text { Lin }}$ are calculated with the single molecular model; $k$ and $c$ are unknown and the correction value.

To identify the value of $k$ and $c, 11$ reported polymer electrode materials were collected [44, 51], and their experimental potentials are listed in Table 1. A linear fitting between the calculation values of $\Delta E_{\text {poly }}$ and the values of the experimental potentials is present in Fig. 5, which implies $k=1, c=-0.45, R^{2}=0.59$. Ideally, the slope of the equation should be one. In fact, the slope after fitting was the same as the ideal slope, and the intercept was $-0.45 \mathrm{~V}$. Non-zero intercepts can be derived from the energy difference of lithium in a single-molecule model and the system error between the "computing" and "experimental" environments.

$V_{\text {pre }}=\frac{-\left(E_{\mathrm{A}-\mathrm{Li}_{n}}-E_{\mathrm{A}}\right)}{n F}-0.45$

The verification results of the experiment and calculation are shown in the Fig. 5, where $R^{2}=0.59$, indicating that the experimental and calculated values fit well. The present work is purely theoretical, and the possibilities of 26 industry polymers to be applied as electrode of Li-ion battery have been simulated. The related experiments are out of the present work. Recently, in another published paper (Solid State Ionics 317 (2018) 164-169), PET was reported as electrode material of Li-ion battery, and its experimental potential (about $0.9 \mathrm{~V}$ ) is very close to the theoretical value (about $0.82 \mathrm{~V}$ ) reported in the present work, which further verifies the theoretical method.

In this paper, we apply Eq. (2c) to predict the potentials of the polymer electrode materials for lithium-ion batteries. For the other 26 types of industrial polymer materials, which are not reported previously, their molecular structures are listed in Fig. 6. The predicted potentials are shown in Fig. 7. The potentials of 3 types of materials were higher than $2.0 \mathrm{~V}, 11$ types of materials were between 1.5 and $2.0 \mathrm{~V}$, and 12 types of materials were lower than $1.5 \mathrm{~V}$. Materials with a potential higher than $1.5 \mathrm{~V}$ can be used as cathode materials.

Figure 8 shows that the theoretical capacities of 6 types of materials are higher than $274 \mathrm{mAh} / \mathrm{g}$ (the capacity of $\mathrm{LiCoO}_{2}$ ), and of 21 types are higher than $170 \mathrm{mAh} / \mathrm{g}$ (the capacity of $\mathrm{LiFePO}_{4}$ ). Most polymer materials have a higher capacity compared with inorganic materials.

The band gaps of the 26 types of industrial polymer materials are shown in Fig. 9, in which the blue bars represent the
Fig. 8 Theoretical capacity of 26 types of industrial polymer materials
Theoretical Capacity $(\mathrm{mAh} / \mathrm{g})$

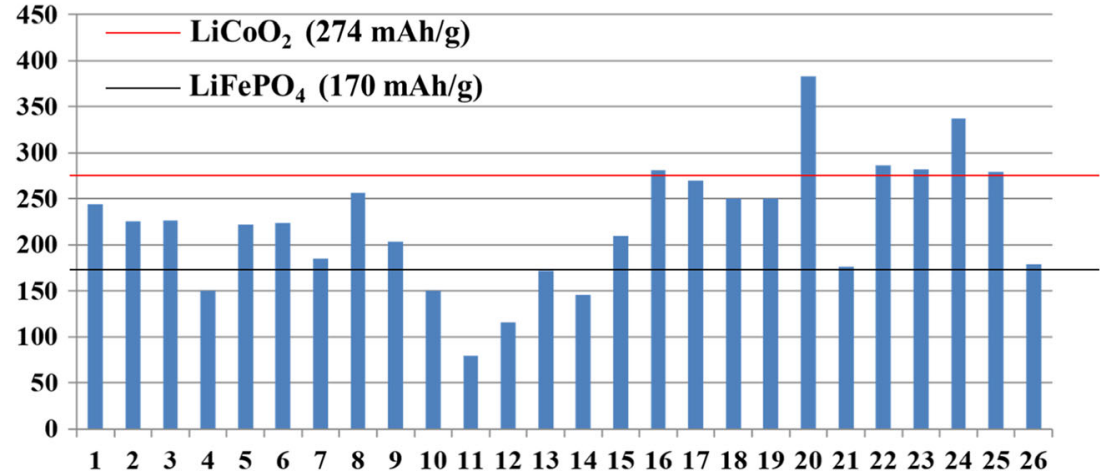


Fig. 9 Band gaps of 26 types of industrial polymer materials
Band gap

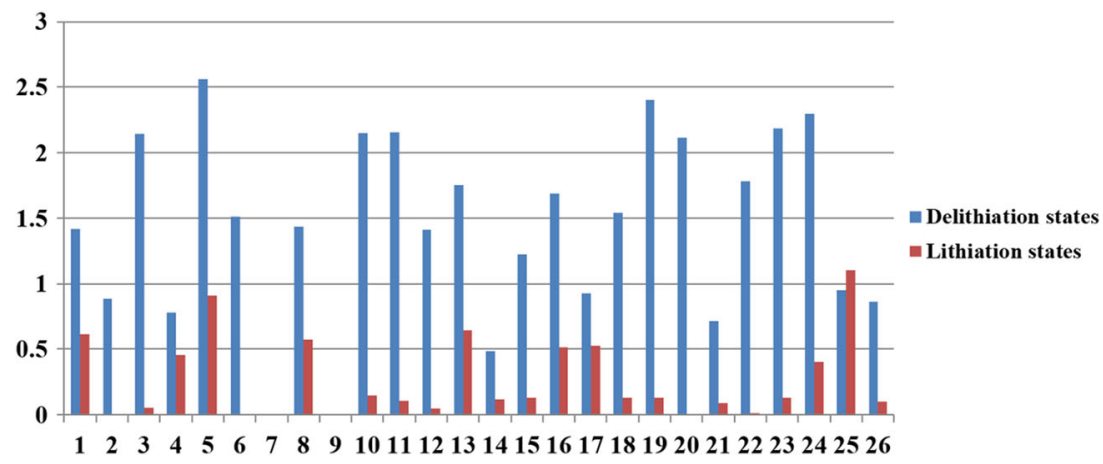

delithiated states, and the red bars represent the lithiated states. For each material, the band gap of the delithiated state is significantly different from the lithiated state, which is primarily observed because the intercalated lithium ions greatly change the interaction between industrial polymers. The band gap of $\mathrm{LiFePO}_{4}$ is $3.1 \mathrm{eV}$, the band gap of NCM (nickel cobalt manganese ternary material) is $1.95 \mathrm{eV}$, and the band gap of sulfur is about $3.1 \mathrm{eV}$. The band gaps of the 26 materials are all less than $2.7 \mathrm{eV}$, and the band gaps of most materials are smaller than that of typical inorganic materials, indicating that the polymer materials have good electronic conductivity.

The predicted potentials, theoretical capacity, and band gap of 26 types of industrial polymer materials are provided in Fig. 10. Good cathode materials for lithium batteries require large potentials, high capacity, and small band gaps. There are 6 types of materials' with theoretical capacities higher than $274 \mathrm{mAh} / \mathrm{g}$ (the capacity of $\mathrm{LiCoO}_{2}$ ). In the above discussion, the 20th material has high capacity, but its potential is not ideal. The potential of the ninth material is higher than $2.0 \mathrm{~V}$, but the theoretical capacity of the ninth was $203.1 \mathrm{mAh} / \mathrm{g}$, and its theoretical capacity was not ideal. Although other materials except for the 16th, 17th, and 23rd also have small band gap values before and after lithium insertion, their potential and theoretical capacity was not outstanding. There were 12 types of industrial polymer materials that have potentials below $1.5 \mathrm{~V}$; therefore, those industrial polymers might be used as anode materials.
Thus, three industrial polymers were highlighted: 16th, 17 th, and 23rd. The potentials of 16th and 17 th were $2.03 \mathrm{~V}$ and $2.00 \mathrm{~V}$, respectively, and the potential of the $23 \mathrm{rd}$ was $1.95 \mathrm{~V}$. The capacity of the 16th and 23rd were higher than $274 \mathrm{mAh} / \mathrm{g}$, and the capacity of the $17 \mathrm{th}$ was $269.4 \mathrm{mAh} / \mathrm{g}$, which was close to $274 \mathrm{mAh} / \mathrm{g}$. The band gaps of the $17 \mathrm{th}$ before and after lithium insertion were $0.93 \mathrm{eV}$ and $0.53 \mathrm{eV}$, respectively. The band gaps of the 16 th before and after lithium insertion were $1.69 \mathrm{eV}$ and $0.51 \mathrm{eV}$, respectively. The band gaps of the 23rd before and after lithium insertion were $2.19 \mathrm{eV}$ and $0.13 \mathrm{eV}$, respectively. The band gaps show that they have good electronic conductivity and dynamic performance in Li-ion batteries. The high capacity, high potential, and small band gaps were positive factors for the three industrial polymer materials to be electrode materials.

In this work, three polymer electrode materials (with a relatively high potential, high capacity, and small band gap), 16th, 17 th, and 23rd, were highlighted from 26 types of industrial polymers. The 16th, 17th, and 23rd materials have similar structures and similar potentials. Therefore, the following studies of the three materials (16th, 17th, and 23rd) with similar structure were made.

It is difficult to set up a general rule to coarsely identify the potentials and band gaps of the polymers. So, we researched three different polymer materials (Fig. 11) which have the similar structure. We investigated how the heteroatom and substituent identity $\left(X=\mathrm{O}, \mathrm{S}\right.$, or $\left.\mathrm{CH}_{2}\right)$ in the structure affected
Fig. 10 Predicted potentialtheoretical capacity band gap map of 26 types of industrial polymer materials

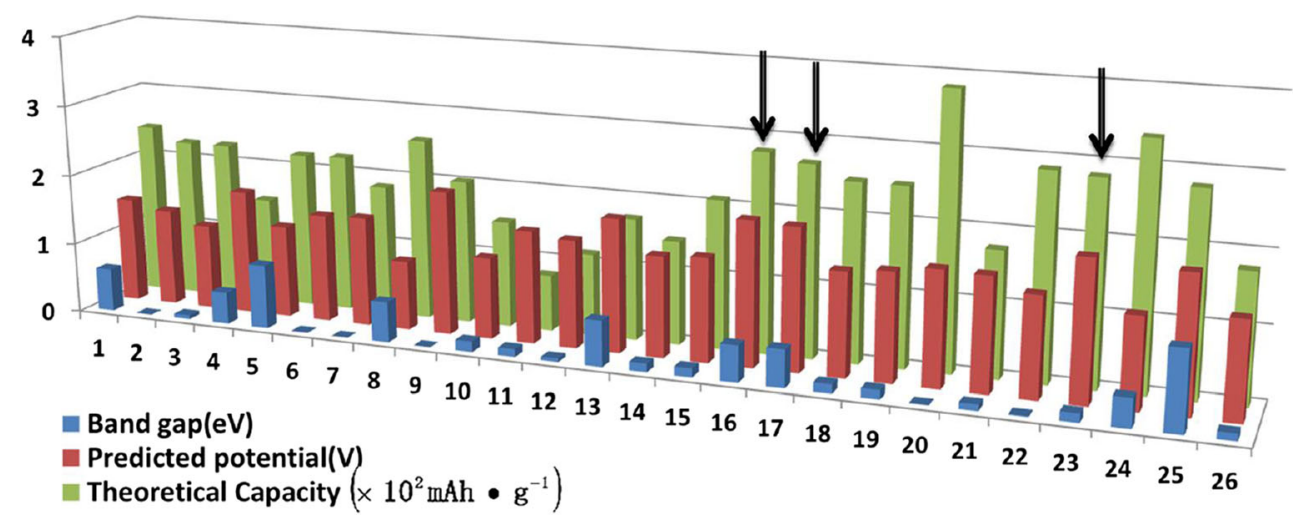


Fig. 11 a Potentials of the 16th, 17 th, and 23rd materials; $\mathbf{b}$ LUMO and HOMO orbital energy values of the 16th, 17th, and 23rd materials; $\mathbf{c}$ repeating units of 16th, 17th, and 23rd materials
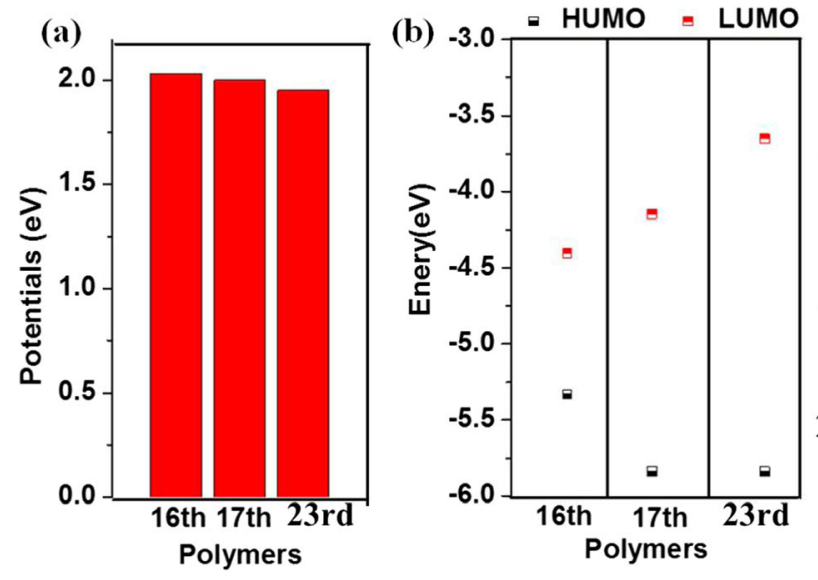

the potentials of materials. The highest potential of $2.03 \mathrm{~V}$ was obtained when oxygen was used as the heteroatom. The material with sulfur as the heteroatom had a potential of $2.0 \mathrm{~V}$, which was slightly lower than oxygen. The material with methylene $\left(\mathrm{CH}_{2}\right)$ as the substituent had the lowest potential of $1.95 \mathrm{~V}$ in the three polymer materials. The potentials of materials could be explained by the energy of LUMO. In the reduction process, the electrons go into the LUMO, which means that the higher the energy of LUMO is, the more difficult it is to enter. When comparing the LUMO energy values of polymers containing $\mathrm{S}, \mathrm{O}$, and $\mathrm{CH}_{2}$, we noticed that the potential values follow the order: 16 th $>17$ th $>23$ rd. This behavior can be explained by the following: the methylene group is the electron-donating group, when the LUMO orbital energy value increases, the electrons will be unable to enter the LUMO orbital, meaning that that the potential is its lowest. The electronegativity of the sulfur atom was less than the electronegativity of the oxygen atom; therefore, the electrondonating ability of the sulfur atom was higher than that of the oxygen atom. This property caused the LUMO orbital energy value to be higher than that of the oxygen atom, making its potential lower than that of the oxygen atom. Therefore, a material containing a low electronegative heteroatom and an electron-donating group has a low potential value. Therefore, the electrochemical properties of materials can be improved by changing the heteroatoms in the structure.

Then, the polymer containing a high electronegative heteroatom and electron-absorbing groups has a relatively high potential and small band gap. For capacity, the material with a larger amount of carbonyl groups and a smaller molar mass has a larger theoretical capacity.

\section{Conclusions}

The charge/discharge potentials of 11 reported polymer electrode materials for lithium-ion batteries were collected, and the experimental values were fitted linearly with the values of
$\Delta E_{\text {poly }}$ (as shown in Eq. (2b)) calculated with the singlemolecule model. After the mathematical treatment, a semiempirical formula was employed to predict charge/discharge potentials of more than 20 industrial polymers as electrode materials. The potential energy range of 26 types of industrial polymers was $0.62 \sim 2.03 \mathrm{~V}$, the capacity distribution was 79.5 382.9 $\mathrm{mAh} / \mathrm{g}^{-1}$, and all band gaps were less than $2.57 \mathrm{eV}$. The 16th, 17th, and 23rd materials are highlighted from 26 types of industrial polymers which have better electrochemical performance than the other materials in this paper. We also found that the electrochemical properties of materials can be improved by changing the heteroatoms in the structure. More polymer electrode materials can be developed with the present theoretical method. We believe that the results of this study will help in designing better electrode materials.

Funding information The study was supported by the fundamental research project of Qinghai province (2017-ZJ-795).

Open Access This article is distributed under the terms of the Creative Commons Attribution 4.0 International License (http:// creativecommons.org/licenses/by/4.0/), which permits unrestricted use, distribution, and reproduction in any medium, provided you give appropriate credit to the original author(s) and the source, provide a link to the Creative Commons license, and indicate if changes were made.

\section{References}

1. Armand M, Tarascon JM (2008) Building better batteries. Nature 451:652

2. Tarascon JM (2010) Key challenges in future Li-battery research. Philosophical Transactions of the Royal Society of London A, Mathematical. Phys Eng Sci 368:3227-3241

3. Mizushima K, Jones PC, Wiseman PJ, Goodenough JB (1980) $\mathrm{LixCoO}_{2}(0<\mathrm{x}<-1)$ : a new cathode material for batteries of high energy density. Mater Res Bull 15:783-789

4. Arico AS, Bruce P, Scrosati B, Tarascon JM, \& Van Schalkwijk W (2011) Nanostructured materials for advanced energy conversion and storage devices. In Materials for sustainable energy: a collection of peer-reviewed research and review articles from Nature Publishing Group 148-159 
5. Kang K, Meng YS, Bréger J, Grey CP, Ceder G (2006) Electrodes with high power and high capacity for rechargeable lithium batteries. Science 311:977-980

6. Venkateswara Rao C, Leela Mohana Reddy A, Ishikawa Y, Ajayan PM (2011) LiNi1/3Co1/3Mn1/3O $\mathrm{O}_{2}$-graphene composite as a promising cathode for lithium-ion batteries. ACS Appl Mater Interfaces 3:2966-2972

7. Lupi C, Pasquali M, Dell'Era A (2005) Nickel and cobalt recycling from lithium-ion batteries by electrochemical processes. Waste Manag 25:215-220

8. Recham N, Chotard JN, Dupont L, Delacourt C, Walker W, Armand M, Tarascon JM (2010) A 3.6 V lithium-based fluorosulphate insertion positive electrode for lithium-ion batteries. Nat Mater 9:68

9. Chen H, Armand M, Demailly G, Dolhem F, Poizot P, Tarascon JM (2008) From biomass to a renewable LiXC6O6 organic electrode for sustainable Li-ion batteries. ChemSusChem 1:348-355

10. Song Z, Zhou H (2013) Towards sustainable and versatile energy storage devices: an overview of organic electrode materials. Energy Environ Sci 6:2280-2301

11. Chen H, Armand M, Courty M, Jiang M, Grey CP, Dolhem F, Poizot P (2009) Lithium salt of tetrahydroxybenzoquinone: toward the development of a sustainable Li-ion battery. J Am Chem Soc 131:8984-8988

12. Walker W, Grugeon S, Mentre O, Laruelle S, Tarascon JM, Wudl F (2010) Ethoxycarbonyl-based organic electrode for Li-batteries. J Am Chem Soc 132:6517-6523

13. Novák P, Müller K, Santhanam KSV, Haas O (1997) Electrochemically active polymers for rechargeable batteries. Chem Rev 97:207-282

14. Snook GA, Kao P, Best AS (2011) Conducting-polymer-based supercapacitor devices and electrodes. J Power Sources 196:1-12

15. Nakahara K, Iwasa S, Satoh M, Morioka Y, Iriyama J, Suguro M, Hasegawa E (2002) Rechargeable batteries with organic radical cathodes. Chem Phys Lett 359:351-354

16. Lu H, Sun S (2018) Polyimide electrode materials for Li-ion batteries via dispersion-corrected density functional theory. Comput Mater Sci 146:119-125

17. Huang KW (2013) Redox Behaviors of nitroxide radical polymers studied by in-situ raman measurement and molecular dynamics simulation.

18. Kassam A, Burnell DJ, Dahn JR (2011) Lithiated 1, 4, 5, 8naphthalenetetraol formaldehyde polymer, an organic cathode material. Electrochem Solid-State Lett 14:A22-A23

19. Song Z, Zhan H, Zhou Y (2010) Polyimides: promising energystorage materials. Angew Chem Int Ed 49:8444-8448

20. Walker W, Grugeon S, Vezin H, Laruelle S, Armand M, Tarascon JM, Wudl F (2010) The effect of length and cis/trans relationship of conjugated pathway on secondary battery performance in organolithium electrodes. Electrochem Commun 12:1348-1351

21. Yao M, Araki M, Senoh H, Yamazaki SI, Sakai T, Yasuda K (2010) Indigo dye as a positive-electrode material for rechargeable lithium batteries. Chem Lett 39:950-952

22. Zeng RH, Li XP, Qiu YC, Li WS, Yi J, Lu DS, Xu MQ (2010) Synthesis and properties of a lithium-organic coordination compound as lithium-inserted material for lithium ion batteries. Electrochem Commun 12:1253-1256

23. Gao XP, Yang HX (2010) Multi-electron reaction materials for high energy density batteries. Energy Environ Sci 3:174-189

24. Xiang J, Chang C, Li M, Wu S, Yuan L, Sun J (2007) A novel coordination polymer as positive electrode material for lithium ion battery. Cryst Growth Des 8:280-282

25. Han X, Chang C, Yuan L, Sun T, Sun J (2007) Aromatic carbonyl derivative polymers as high-performance li-ion storage materials. Adv Mater 19:1616-162
26. Zhou W, Hernández-Burgos K, Burkhardt SE, Qian H, Abruña HD (2013) Synthesis and electrochemical and computational analysis of two new families of thiophene-carbonyl molecules. J Phys Chem C 117:6022-6032

27. Chen Y, Luo W, Carter M, Zhou L, Dai J, Fu K, Bao Y (2015) Organic electrode for non-aqueous potassium-ion batteries. Nano Energy 18:205-211

28. Wu H, Wang K, Meng Y, Lu K, Wei Z (2013) An organic cathode material based on a polyimide/CNT nanocomposite for lithium ion batteries. J Mater Chem A 1:6366-6372

29. Gracia R, Mecerreyes D (2013) Polymers with redox properties: materials for batteries, biosensors and more. Polym Chem 4: 2206-2214

30. Janoschka T, Hager MD, Schubert US (2012) Powering up the future: radical polymers for battery applications. Adv Mater 24: 6397-6409

31. Oyaizu K, Nishide H (2009) Radical polymers for organic electronic devices: a radical departure from conjugated polymers? Adv Mater 21:2339-2344

32. Wang L, He X, Sun W, Li J, Gao J, Tian G, Fan S (2013) Organic polymer material with a multi-electron process redox reaction: towards ultra-high reversible lithium storage capacity. RSC Adv 3: 3227-3231

33. Simmonds AG, Griebel JJ, Park J, Kim KR, Chung WJ, Oleshko VP, Sung YE (2014) Inverse vulcanization of elemental sulfur to prepare polymeric electrode materials for $\mathrm{Li}-\mathrm{S}$ batteries. ACS Macro Lett 3:229-232

34. Deng W, Liang X, Wu X, Qian J, Cao Y, Ai X, Yang H (2013) A low cost, all-organic Na-ion battery based on polymeric cathode and anode. Sci Rep 3:2671

35. Shi S, Gao J, Liu Y, Zhao Y, Wu Q, Ju W, Xiao R (2015) Multiscale computation methods: their applications in lithium-ion battery research and development. Chinese Physics B 25:018212

36. Häupler B, Wild A, Schubert US (2015) Carbonyls: powerful organic materials for secondary batteries. Adv Energy Mater 5: 1402034

37. Sharma P, Damien D, Nagarajan K, Shaijumon MM, Hariharan M (2013) Perylene-polyimide-based organic electrode materials for rechargeable lithium batteries. The Journal of Physical Chemistry Letters 4(19):3192-3197

38. Geng J, Bonnet JP, Renault S, Dolhem F, Poizot P (2010) Evaluation of polyketones with $\mathrm{N}$-cyclic structure as electrode material for electrochemical energy storage: case of tetraketopiperazine unit. Energy Environ Sci 3(12):1929-1933

39. Liu K, Zheng J, Zhong G, Yang Y (2011) Poly (2, 5-dihydroxy-1, 4-benzoquinonyl sulfide) (PDBS) as a cathode material for lithium ion batteries. J Mater Chem 21(12):4125-4131

40. Zhao L, Wang W, Wang A, Yuan K, Chen S, Yang Y (2013) A novel polyquinone cathode material for rechargeable lithium batteries. J Power Sources 233:23-27

41. Le Gall T, Reiman KH, Grossel MC et al (2003) Poly (2, 5-dihydroxy-1, 4-benzoquinone-3, 6-methylene): a new organic polymer as positive electrode material for rechargeable lithium batteries. J Power Sources 119:316-320

42. Song Z, Zhan H, Zhou Y (2009) Anthraquinone based polymer as high performance cathode material for rechargeable lithium batteries. Chem Commun (4):448-450

43. Song Z, Qian Y, Gordin ML (2015) Polyanthraquinone as a reliable organic electrode for stable and fast lithium storage. Angew Chem 127(47):14153-14157

44. Xie J, Wang Z, Xu ZJ, Zhang Q (2018) Toward a high-performance all-plastic full battery with a single organic polymer as both cathode and anode. Adv Energy Mater 8:1703509

45. Sun P, Lu H, Zhang W, Wu H, Sun S, Liu X (2018) Poly (ethylene terephthalate): rubbish could be low cost anode material of lithium ion battery. Solid State Ionics 317:164-169 
46. Nokami T, Matsuo T, Inatomi Y, Hojo N, Tsukagoshi T, Yoshizawa H, Yoshida JI (2012) Polymer-bound pyrene-4, 5, 9, 10-tetraone for fast-charge and-discharge lithium-ion batteries with high capacity. $\mathrm{J}$ Am Chem Soc 134:19694-19700

47. Karlsson C, Jämstorp E, Strømme M, Sjödin M (2012) Computational electrochemistry study of 16 isoindole-4, 7-diones as candidates for organic cathode materials. J Phys Chem C 116: 3793-3801

48. Burkhardt SE, Bois J, Tarascon JM, Hennig RG, Abruña HD (2013) Li-carboxylate anode structure-property relationships from molecular modeling. Chem Mater 25:132-141

49. Hernández-Burgos K, Burkhardt SE, Rodríguez-Calero GG, Hennig RG, Abruña HD (2014) Theoretical studies of carbonylbased organic molecules for energy storage applications: the heteroatom and substituent effect. J Phys Chem C 118:6046-6051

50. Sun S, Chen Y, Yu J (2015) High throughput screening of organic electrode materials for lithium battery by theoretical method. J Phys Chem C 119:25770-25777

51. Chen Y, Sun S, Wang X, Shi Q (2015) Study of lithium migration pathways in the organic electrode materials of Li-battery by dispersion-corrected density functional theory. J Phys Chem C 119:25719-25725

52. Chen Y, Wu Z, Sun S (2014) First-principles study of an ethoxycarbonyl-based organic electrode material of lithium battery. J Phys Chem C 118:21813-21818

53. Te Velde GT, Bickelhaupt FM, Baerends EJ, Fonseca Guerra C, van Gisbergen SJ, Snijders JG, Ziegler T (2001) Chemistry with ADF. J Comput Chem 22:931-967

54. Zhang W, Sun P, Sun S (2017) A precise theoretical method for high-throughput screening of novel organic electrode materials for Li-ion batteries. Journal of Materiomics 3:184-190

55. Guerra CF, Snijders JG, te Velde GT, Baerends EJ (1998) Towards an order-N DFT method. Theor Chem Accounts 99:391-403

Publisher's note Springer Nature remains neutral with regard to jurisdictional claims in published maps and institutional affiliations. 